\title{
Focusing on the Relationship between Speaking Fluency/Accuracy of EFL Learners of Both Genders and their Listening Comprehension
}

\author{
Mohammad Saber Khaghaninejad (Corresponding author) \\ Department of Foreign Languages and Linguistics, Shiraz University, Iran \\ Email: mskhaghani@shirazu.ac.ir
}

\author{
Mahsa Bahrani \\ M.A. in English Teaching as a Foreign Language (TEFL), Iran \\ Email: bahrani.mahsa@gmail.com
}

Doi:10.5901/mjss.2016.v7n3p444

\section{Abstract}

\begin{abstract}
This study sought to investigate the role of gender on Iranian intermediate learners' oral accuracy and fluency. It also attempted to explore which one speaking fluency or accuracy had a more meaningful relationship with the participants' listening comprehension. Initially, out of 20 intermediate classes 3 classes of female and 3 classes of male learners comprising a total number of 45 male and 45 learners were selected randomly from the pool of Tehran Institute of Technology. A validated pretest was administered to the participants to assure homogeneity in terms of overall language proficiency and accordingly, 30 male and 30 female learners were identified as the legitimate participants who had been interviewed drawing on the some speaking tasks. The speech of the participants were recorded and subsequently analyzed by two raters based on the fluency and accuracy measurement criteria. Inter-rater reliability was established for both the fluency and accuracy $(87 \%$ and $83 \%$, respectively). Having finished the analysis of the participants' performance, the researcher administered the listening comprehension test. The obtained data were analyzed to investigate the role of gender on oral accuracy and fluency and their possible correlations with listening comprehension performance. The results indicated that female participants outperformed the males in terms of fluency while males were superior in terms of accuracy. Moreover, it was found that a strong correlation existed between female participants' listening comprehension and speaking fluency while for the male participants this correlation existed with the speaking accuracy.
\end{abstract}

Keywords: Listening Comprehension, Gender, Speaking accuracy and fluency, Correlation

\section{Introduction}

Although the role of gender and its consequences has been interesting for the researchers, to the best knowledge of the researchers very few studies are based on the empirical documentation of the gender effect on fluency and accuracy in speaking which is the result of surveying a group of subjects. By choosing the subjects from the specific level of proficiency randomly, this study can possibly push the frontiers of knowledge in order to look for justification, and also solution any kind of difference in terms of oral accuracy and fluency of male and female participants of the study. The study is deemed to be helpful for developing academic speaking instruction materials and classroom activities. This study tried to fill the theoretical gap in the literature regarding the role of gender and its effect on speaking accuracy and fluency and endeavored to unearth the possible relationship between the participants' speaking accuracy/fluency and their performance on listening comprehension tasks; this experiment's objective was to discover the potential connection between oral English skills and the role of participants' gender in this regard. In better words, the enquiry was an effort to ascertain empirically reasonable answers to the following research questions:

- Does Iranian English learners' gender have any effect on their English speaking accuracy/fluency?

- Which one of speaking fluency or speaking accuracy can be more affected by the Iranian learners' gender?

- Which one of speaking fluency or speaking accuracy is more related to the participants' listening comprehension of each gender? 


\section{Method}

\subsection{Participants}

Subjects_The finalized participants of this study were 30 Iranian male and 30 Iranian female intermediate EFL learners. They were selected randomly from 20 intermediate classes at Tehran Institute of Technology where the experimentation took place. Initially, three female and three male classes were selected. They were all adults and their age ranged from 20 to 35. These participants had already received an approximate number of 300 hours of English language instruction. The course book being utilized by the institute at the time of this investigation was Top Notch (Ascher \& Saslow, 2012) comprising 6 units, which were taught per-term (52 hours).

Raters_In order to come up with reliable scores of accuracy and fluency two experienced speaking instructors who had M.A in TEFL cooperated with the researchers. One of the raters had 8 and the other 9 years of English teaching experience at different language institutes. They had both taught to learners of different proficiency levels and age groups.

\subsection{Materials and instruments}

The materials and instruments used for the purposes of this study were:

Preliminary English Test (PET)_It was administered to make sure that learners were homogenous with respect to their language proficiency at the very beginning of the enquiry. Preliminary English Test (PET) is a qualification in English as a foreign language awarded by Cambridge TESOL. The test which has three sections of mixed reading/writing, listening and speaking is considered a complete test of English proficiency due to the fact that it covers all the linguistic skills. PET was administered to the participants and those whose scores fell within the range of one standard deviation above and below the mean were selected as the legitimate participants of the study. In other words only the participants whose scores lay under the normal curve were chosen. To this end 30 female and 30 male learners were chosen.

Fluency Measurement Scale_ For measuring the speaking fluency, the speech samples were transcribed and fluency was calculated in terms of the variables proposed by Kormos and Denes's (2004) Mean length of runs, Articulation rate, Speech rate and The number of silent pauses per minute.

Accuracy Measurement Scale_In the current study accuracy was measured in terms of error-free T-units (Sachs \& Polio, 2007, p. 24) which are defined as the "shortest grammatically allowable sentences into which spoken or written text can be divided." A T-unit is a dominant clause and its dependent clauses; all the main clauses in addition to their subordinate and embedded clauses were counted as T-units in this study. Inspired by Storch (2009), only those T-units that contained no grammatical, syntactic, and lexical errors were counted as acceptable T-units. To measure accuracy, the number of acceptable T-units was divided by the total number of t-units (Storch, 2009). The result was then multiplied by 100 to obtain the accuracy percentage.

Interview Tasks_ Since the learners were all at the intermediate level of proficiency, the interview tasks used to assess learners' speaking accuracy and fluency were chosen from the bank of PET speaking tasks. In the first part of these tasks, the examiner introduced herself and asked the participants' name and personal information and asked them to spell their names. In part two, the examiner gave the participants a picture and asked them to talk about it together. In part three, each participant was given the chance to speak alone; the examiner provided the participant with a colored photograph and asked the learner to talk about. The examiners interviewed each participant in a 10-12 minute interview.

Listening Test_In order to obtain the scores of the participants on listening comprehension and neutralize the effect of familiarity with the test items, the listening section of PET from another version of the test other than the one used for homogeneity purposes was administered to learners. The test also used to check which one of accuracy or fluency had a stronger correlation with listening comprehension.

\subsection{Procedure}

Initially, out of 20 intermediate classes 3 classes of female and 3 classes of male learners (comprising a total of 45 male and 45 learners) were selected randomly at Tehran Institute of Technology. PET was administered to the participants to assure homogeneity in terms of overall language proficiency. Base on the normal curve 30 male and 30 female learners were identified as the legitimate participants. Following that, each participant was interviewed drawing on the speaking tasks of PET which had already been chosen randomly from a bank of speaking tasks. The speech products of the participants were recorded and subsequently analyzed by two raters based on the fluency and accuracy measurement 
criteria, respectively. Inter-rater reliability was established through running Pearson Correlation Coefficient Formula on the two sets of scores for fluency and accuracy. Having finished the analysis of the participants' performance in terms of accuracy and fluency, the researcher administered the listening tasks of PET. In the next phase the data obtained were analyzed to investigate the role of gender on Iranian intermediate learners' oral accuracy and fluency and their possible correlation with listening comprehension performance.

\subsection{Design}

As for the design of the study it should be mentioned that it employed a quantitative research design; in addition to descriptive analysis, quantitative analyses were done to compare the performances of the groups in terms of speaking fluency and accuracy via a set of independent-samples t-tests. Moreover, the correlations between speaking fluency and accuracy and listening comprehension were calculated with the aid of Pearson correlation coefficient measurement.

\section{Data Analysis and Discussion}

\subsection{Results}

In order to be able to test the null hypotheses of the study, first it was deemed necessary to homogenize the male and female participants in terms of overall language proficiency. Hence, PET was given to the 90 initial subjects selected randomly from a previously-mentioned pool. Table 1 and Figure 1 display descriptive statistics and the histogram of the participants' on the initial PET, respectively.

Table 1. Descriptive Statistics of the Original 90 Intermediate Participants' PET Scores

\begin{tabular}{cccccc}
\hline & N & Minimum & Maximum & Mean & Std. Deviation \\
\hline PET Scores & 90 & 28.00 & 50.00 & 38.82 & 5.429 \\
\hline
\end{tabular}

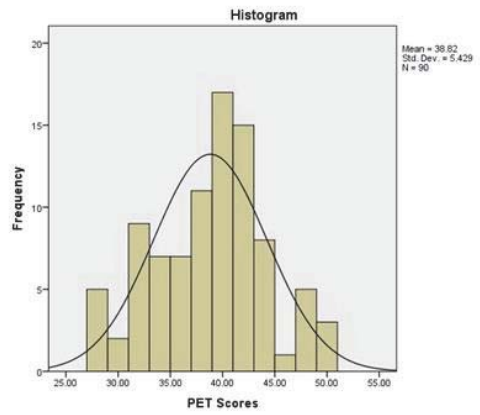

Figure 1. Histogram of the Initial 90 Intermediate Participants

As it can be noticed the mean score is 38.82 and the standard deviation is 5.429 . Drawing on this data, the researcher excluded the participants whose scores fell beyond one standard deviation above and below the mean leading to the selection of 60 homogeneous participants i.e. 30 male and 30 female for the purposes of this study. Next, in order to assure that these two groups were not significantly different in terms of language proficiency an Independent samples ttest was also run on the PET scores of the two groups. Tables 2 and 3 show the descriptive statistics and the mean comparison results of the PET scores of the male and female groups, respectively.

Table 2. Descriptive statistics of the male and female groups on PET

N Mean Std. DeviationStd. Error Mean

\begin{tabular}{cccc}
\hline PET Female and Male Groups $\frac{\text { Female Group PET3039.5667 }}{n}$ & 1.50134 & .27411 \\
\cline { 2 - 4 } & Male Group PET 3039.4667 & .50742 & .09264 \\
\hline
\end{tabular}


Table 3. Mean comparison of males and females on pre-test PET

\begin{tabular}{lccccc}
\hline PET Groups & N & SD & t & DF & Sig. \\
\hline PET Female Group & 30 & 1.50134 & .346 & 58 & 0.73 \\
\hline PET Male Group & 30 & .50742 & & & \\
\hline
\end{tabular}

As it is discernible the level of significance is 0.731 which is higher than the confidence level of 0.05 leading to the conclusion that there was not any significant difference between the overall proficiency of the participants in the male and female groups at the beginning of the enquiry. The first research question was explored by running an independent samples t-test on the fluency scores of the female and male groups of the study. Tables 4 and 5 display the descriptive statistic and the results of the comparison, respectively.

Table 4. Descriptive statistics of the male and female groups' on the fluency test

\begin{tabular}{llll}
\hline & \multicolumn{3}{c}{$\mathbf{N}$ Mean Std. DeviationStd. Error Mean } \\
\hline \multirow{2}{*}{ Male and Female Group Fluency Male Group 3041.2823} & 4.4758 & .34522 \\
\cline { 2 - 4 } Female Group3045.2635 & 5.3232 & .82526 \\
\hline
\end{tabular}

Table 5. Mean comparison of males and females fluency test scores

\begin{tabular}{lccccc}
\hline Fluency & N & SD & t & DF & Sig. \\
\hline Female Group & 30 & 5.3232 & 7.214 & 58 & .023 \\
\hline Male Group & 30 & 4.4758 & & & \\
\hline
\end{tabular}

As Table 5 displays, the level of significance is 0.023 which is lower than the confidence level of 0.05 leading to the conclusion that there was a significant difference between the fluency of the participants in the male and female groups. Moreover, Table 4 indicates that the mean of the participants' scores for the female group was higher than that of the male group (M Female $=45.2635>41.2823=$ M Male). Thus, it could be inferred that female participants outperforming male participants significantly in terms of speaking fluency. Furthermore, another independent-samples t-test was employed on the accuracy scores of the study's participants to be capable of expressing a defendable answer to the first research question. Tables 6 and 7 display the descriptive statistics and the results of the mean comparison, respectively.

Table 6. Descriptive statistics of the male and female groups' on the accuracy test

\begin{tabular}{llllll}
\hline Male and Female Groups Accuracy & \multicolumn{1}{c}{ N Minimum } & Maximum & Mean & Std. Deviation \\
\hline Female Group Accuracy & 30 & 10.00 & 20.00 & 17.1025 & 2.52404 \\
\hline Male Group Accuracy & 30 & 15.00 & 24.00 & 22.8387 & 1.32876 \\
\hline
\end{tabular}

Table 7. Mean comparison of males and females accuracy test scores

\begin{tabular}{lccccc}
\hline Accuracy & $\mathrm{N}$ & $\mathrm{SD}$ & $\mathrm{t}$ & $\mathrm{DF}$ & Sig. \\
\hline Female group & 30 & 2.5240 & -4.791 & 58 & .007 \\
\hline Male Group & 30 & 1.3287 & & & \\
\hline
\end{tabular}

As Table 7 signifies the significance level is .007 which is lower than .05 meaning that there was a statistically significant difference between the means of accuracy scores of the male and female groups. Moreover, Table 6 illustrates that the mean of the participants' scores for the male group is higher than that of the female group (M Male $=22.8387>17.1025=$ M Female). Consequently, it could be concluded that male participants outperforming female participants in terms of speaking accuracy remarkably. Considering Tables 5 and 7, it could noticeably be inferred that the female group had a better performance in terms of speaking fluency and the male group had a better performance regarding speaking accuracy; speaking fluency was more affected by the female participants while speaking accuracy was more affected by male learners. The third research question of the study was probed by running Pearson Correlation Coefficient analytic technique. The main assumption for Pearson Correlation Coefficient is the assumption of normality. Table 8 demonstrates the results of One-Sample Kormogorov-Smirnov Test of normality for the listening comprehension, and accuracy and fluency scores of the male and female groups. 
Table 8. Results of One-Sample Kormogorov-Smirnov Test of normality

\begin{tabular}{lrccc}
\hline & \multicolumn{3}{c}{ Normal Parameters ${ }^{\mathrm{a}, \mathrm{b}}$} \\
\cline { 2 - 5 } & \multicolumn{2}{c}{ Mean Std. Deviation } & \multirow{2}{*}{ Kormogorov-Smirnov ZAsymp. Sig. (2-tailed) } \\
\hline Fluency Males & 3041.2823 & 4.4758 & .894 & .401 \\
Fluency Female & 3045.2635 & 5.3232 & .937 & .344 \\
\hline Listening comprehension Males & 3016.5294 & 2.10678 & .685 & .736 \\
Listening comprehension Females3017.2129 & 2.41768 & 1.162 & .134 \\
\hline Accuracy Females & 3017.1025 & 2.52404 & .835 & .489 \\
Accuracy Male & 3022.8387 & 1.32876 & 1.335 & .056 \\
\hline
\end{tabular}

As the table shows all the significance levels are above 0.05 indicating that the six score sets were all normally distributed (Tabachnick \& Fidell, 2007). Upon assuring the normal distribution of the data sets, the researchers decided to use the parametric test of Pearson Correlation Coefficient to explore the fourth null hypothesis. Table 9 demonstrates the results of this analysis.

Table 9. Correlation coefficient indices of accuracy and fluency and listening comprehension scores of male and female participants

\begin{tabular}{|c|c|c|c|}
\hline & & Listening Scor & Scores Female \\
\hline & Pearson Correlation & 1 & -.063 \\
\hline Listening Scores Male & Sig. (2-tailed) & & .739 \\
\hline & $\mathrm{N}$ & 30 & 30 \\
\hline & Pearson Correlation & -.063 & 1 \\
\hline Listening Scores Female & Sig. (2-tailed) & .739 & \\
\hline & $\mathrm{N}$ & 30 & 30 \\
\hline & Pearson Correlation & $.389 * \star$ & -.195 \\
\hline Accuracy Scores Male & Sig. (2-tailed) & .002 & .301 \\
\hline & $\mathrm{N}$ & 30 & 30 \\
\hline & Pearson Correlation & .007 & .253 \\
\hline Accuracy Scores Female & eSig. (2-tailed) & .971 & .178 \\
\hline & $\mathrm{N}$ & 30 & 30 \\
\hline & Pearson Correlation & .128 & $.443^{*}$ \\
\hline Fluency Scores Male & Sig. (2-tailed) & .257 & .014 \\
\hline & $\mathrm{N}$ & 30 & 30 \\
\hline & Pearson Correlation & .083 & $.323^{\star \star}$ \\
\hline Fluency Scores Female & Sig. (2-tailed) & .662 & .000 \\
\hline & $\mathrm{N}$ & 30 & 30 \\
\hline
\end{tabular}

As Table 9 depicts there was a significant and positive relationship between female listening comprehension scores and their fluency scores $(r=0.323 p=.000<0.01)$. On the other hand, no significant relationship exists between male participants' listening comprehension scores and their fluency. It was also found that a strong positive correlation existed between male participants' listening comprehension and accuracy scores $(r=0.389 p=.002<0.01)$. However, no significant relationship was revealed for the female participants' listening comprehension and accuracy scores. Therefore, speaking fluency was found to be significantly related to the listening comprehension of female participants of the study and speaking accuracy was significantly related to the listening comprehension of the male participants of the experiment in a statistically justifiable way.3.2 Discussion

This study aimed at examining the role of gender on Iranian intermediate learners' speaking accuracy and fluency. Additionally, the study was an effort in exploring whether speaking fluency or speaking accuracy was more affected by Iranian learners' gender. Moreover, it aimed at probing whether speaking fluency or speaking accuracy was more related to the listening comprehension of each gender's participants. The results of statistical analysis suggested that female participants outperformed the male participants in terms of speaking fluency while male participants had a better performance in terms of speaking accuracy. It was also revealed that speaking accuracy was more affected by male and speaking fluency was more affected by female participants. Moreover, it was found out that a strong correlation existed between female participants' listening comprehension and fluency scores while for the male participants this correlation existed with the speaking accuracy. 
Keefe (1982) argued that the factors that determine these differences are basic physiological differences, such as differences in the development of brain, as well as differences in higher-level cortical functions. In Banich's view (1997) males and females were somehow different in terms of their patterns of lateralization which means males are more lefthemisphere dominant than females. Based on this difference, it can be argued that since the left-brain dominance has got to do with the analytical thinking (Banich, 1997; Khaghaninejad \& Jaafarzadeh, 2014) and analytical ability is important in learning grammar, the male participants in the present study were significantly better than females in terms of speaking accuracy.

This enquiry's findings were in line with what Farahani and Khaghaninejad (2009) found about the difference between the speaking performances of male and female Iranian EFL learners; they mentioned that females are superior in speaking tasks than their male peers. They also proposed that males unlike females are more sensitive to grammatical structures and the accuracy of their sentences.

\section{Conclusion}

The results of statistical analysis showed that female participants outperformed the male participants in terms of fluency while male participants had a better performance in terms of speaking accuracy. It was also revealed that speaking accuracy was more affected by male and speaking fluency was more affected by female participants. Moreover, it was found out that a strong correlation existed between female participants' listening comprehension and fluency scores while for the male participants this correlation existed with the speaking accuracy. One of the demographic characteristics for which substantial significance has been attached to with regard to language learning is learners' gender (Cornbleet \& Carter 2001; Truesdale, 1990). With an aim of finding out whether or not there were any gender differences in students' performance concerning speaking accuracy and fluency, this study aimed at contributing to the existing literature. Based on the findings, it can be stated that gender differences do have an effect on learning different skills and their components; male and female foreign language learners show different capacities for acquiring various linguistic skills (Buck, 2001; Burns, 1998). Therefore, foreign language instructors should be encouraged to take benefit by taking this point into consideration to improve students' performance on different English language skills and sub-skills.

\subsection{Pedagogical implications}

The following instructional implications can be proposed inspired by the findings of the enquiry:

- Material developers may greatly benefit from taking the role of gender in mind when developing materials in order to strike a balance in the instructional materials so that both genders are equally treated and given similar the opportunities for learning a new language.

- Curriculum developers and educational policy makers can also gain benefits from the findings of the present study in the way that for designing curricula they may consider the role gender has when it comes to speaking accuracy and fluency and consequently design activities to compensate for the perceived weaknesses of both genders.

- The learners themselves can be given awareness in terms of how gender can be related to different areas of language learning and thus assisted in the process of language learning. To this end, the areas of strengths and weakness can be elaborated on for the learners by the teachers.

- In the light of the findings of this study, teachers may intend to consider the strengths and weaknesses of both genders in teaching a new language (e.g., English) and attempt to compensate for the weaknesses by focusing on the strengths of the learners of each gender.

\section{References}

Ascher, M., \& Saslow, P. R. (2012). Handbook of self-regulation. San Diego, CA: Academic Press.

Banich M. T. (1997). Breakdown of executive function and goal-directed behavior. In M. T. Banich (Eds.), Neuropsychology: The neural bases of mental function (pp. 369-390). Boston: Houghton Mifflin Company.

Buck, G. (2001). Assessing listening. Cambridge: Cambridge University Press.

Burns, A. (1998). Teaching Speaking. Annual Review of Applied Linguistics, 18(3), 102-123.

Cornbleet, S. \& Carter, R. (2001). The Language of Speech and Writing. London: Routledge.

Farahani, A. \& Khaghaninezhad, M. S. (2009). A Study of Task-based Approach: The Effects of Task- based Techniques, Gender, and Different Levels of Language Proficiency on Speaking Development. Pazhuhesh-e-Zabanha-ye Khareji, 49(4), $23-41$. 
Keefe, J. W. (1982). Student learning styles and brain behavior: Programs. Instrumentation, research: National Association of Secondary School Principals.

Khaghaninezhad, M. S. \& Jaafarzadeh, G. (2014). Investigating the Effect of Reduced Forms Instruction on EFL Learners' Listening and Speaking Abilities. English Language Teaching, 7(1), 159-171.

Kormos, J., \& Dénes, M. (2004). Exploring measures and perceptions of fluency in the Pearson. Allyn \& Bacon publications.

Sachs, R. \& Polio, C. (2007). Learners' use of two types of written feedback on an L2 speech of second language learners. System, 32, $145-164$.

Storch, N. (2009). The interaction between type of contact and type of instruction: Some effects on the L2 proficiency of learners. Studies in Second Language Acquisition, 8, 181-200

Tabachnick, B. G., \& Fidell, L. S. (2007). Using multivariate statistics (5th ed.). Boston: writing task. Studies in Second Language Acquisition 29, 67-100.

Truesdale, S. P. (1990). Whole-body listening: Developing active auditory skills. Language, Speech, and Hearing Services in Schools, 21, 183-184. 